\title{
Advantages of Cold-knife Dissection with Adjunctive Suction Cauterization Adenotonsillectomy: A Useful and Safe Surgical Technique for Pediatric Patients
}

\author{
Jung Mee Park ${ }^{1,2}$, Jae Sang Han ${ }^{1}$, Yeonji Kim ${ }^{1}$, Jae Hyun Seo ${ }^{1}$, and Shi Nae Park ${ }^{1}$ \\ ${ }^{1}$ Department of Otorhinolaryngology-Head and Neck Surgery, Seoul St. Mary's Hospital, College of Medicine, \\ The Catholic University of Korea, Seoul; and ${ }^{2}$ Department of Otorhinolaryngology-Head and Neck Surgery, Gangneung Asan Hospital, \\ College of Medicine, University of Ulsan, Gangneung, Korea
}

콜드 나이프 절개와 석션 소작술을 이용한 편도 및 아데노이드 절제술의 장점: 소아 환자를 위한 유용하고 안전한 수술 기법

박정미 $^{1,2} \cdot$ 한재상 $^{1} \cdot$ 김연지 $^{1} \cdot$ 서재현 $^{1} \cdot$ 박시내 $^{1}$

가톨릭대학교 의과대학 서울성모병원 이비인후-두경부외과학교실, ${ }^{1}$ 울산대학교 의과대학 강릉아산병원 이비인후-두경부외과학교실

Received March 23, 2020

Revised July 19,2020

Accepted July 21, 2020

Address for correspondence

Shi Nae Park, PhD

Department of Otorhinolaryngology-

Head and Neck Surgery,

Seoul St. Mary's Hospital,

College of Medicine,

The Catholic University of Korea,

222 Banpo-daero, Seocho-gu,

Seoul 06591, Korea

Tel $+82-2-2258-6215$

Fax +82-2-595-1354

E-mailsnparkmd@catholic.ac.kr
Background and Objectives To introduce cold-knife dissection with adjunctive suction cauterization (CDASC) technique for pediatric adenotonsillectomy and to evaluate the advantages of this technique through short and long-term follow-up results.

Subjects and Method Enrolled in the study were 492 subjects with a mean age of 6.5 years, who underwent adenotonsillectomy via the CDASC technique. Surgical outcomes were evaluated through the postoperative bleeding rate, days of normal diet (as a measure of pain), and improvement of obstructive symptoms at regular follow-up visits. Intraoral photography and lateral neck radiography were analyzed for long-term surgical outcomes.

Results None of the enrolled patients revisited the hospital due to hemorrhage, indicating $0 \%$ immediate and delayed postoperative bleeding with this surgical technique. Most of the patients showed normal diet consumption and activity within 3 days. Postoperative intraoral photography after 6 and 12 months were graded as normal (grade 0 ) in $77.5 \%$ and $79.7 \%$ of the enrolled patients, respectively. Postoperative adenoid to nasopharyngeal ratios were significantly reduced $(p<0.05)$ and no recurrence of snoring and adenoid regrowth were demonstrated during the follow-up period of 12 months.

Conclusion Our CDASC technique seems to have several advantages including less postoperative pain, no postoperative bleeding, less scarring, and no recurrence of preoperative symptoms. We suggest that our CDASC technique is a very useful, safe, and effective method of surgery for pediatric adenotonsillectomy.

Korean J Otorhinolaryngol-Head Neck Surg 2021;64(6):407-15

Key Words Adenoidectomy · Pediatrics · Surgical procedures · Tonsillectomy.

\section{Introduction}

Adenotonsillectomy is one of the most common surgical procedures performed worldwide by otolaryngologists for more than 100 years. Although it is a common surgery, the potential for significant morbidity is inherent in this procedure. ${ }^{1)}$ The most common sources of morbidity include postoperative pain, dehydration, respiratory difficulties, and risks

This is an Open Access article distributed under the terms of the Creative Commons Attribution Non-Commercial License (https://creativecommons.org/licenses/by-nc/4.0) which permits unrestricted non-commercial use, distribution, and reproduction in any medium, provided the original work is properly cited. 
of general anesthesia. Serious complications such as postoperative hemorrhage, airway obstruction, nasopharyngeal stenosis, and adenoid regrowth may also be encountered. Furthermore, it is quite troublesome for surgeons to manage such complications, especially in pediatric patients.

Various surgical techniques are used to perform this operation, including a sharp dissection initially described by Crowe and associates, ${ }^{2)}$ monopolar and bipolar diathermy, cryosurgery, coblation, ultrasonic removal, laser tonsillectomy, and thermal welding. The common goals of newly invented techniques have been to shorten the operation time and reduce potential complications for the comfort of the patient, but especially for the convenience of the surgeon. However, the optimal technique and instrumentation for adenotonsillectomy is still controversial. ${ }^{3)}$ In addition, very few institutions perform long-term follow-up on adenotonsillectomy patients.

Cold dissection and electrodissection are the two most commonly used techniques for adenotonsillectomy. Electrodissection is associated with less immediate bleeding and shorter operating time; however, compared to cold dissection, electrodissection uses heat energy, which may cause thermal injury to the tonsillar fossa, leading to delayed wound healing, and eventually more postoperative pain and delayed bleeding. ${ }^{3,4)}$ In this respect, the traditional cold dissection technique is still considered as the standard method with which to compare the effectiveness and safety of other newer techniques. ${ }^{5}$

As for the perioperative care of pediatric patients after adenotonsillectomy, postoperative pain and decreased oral intake are most critical matters of concern, even without immediate complications such as bleeding. According to a recent study that analyzed after-hours otolaryngology patient phone calls, the most calls were made from mothers of children who went through adenotonsillectomy concerning bleeding, followed by uncontrolled pain, fever, and decreased oral intake.) Unlike operation in an adult, perioperative care in a pediatric patient is often a family based matter; returning to normal life of entire family members depends on the recovery of the patient.

In this study, we report the results of our technique of pediatric adenotonsillectomy, called cold-knife dissection with adjunctive suction cauterization (CDASC). In order to minimize post-operative pain and complications of pediatric patients following adenotonsillectomy, we adopted the advantages of standard cold-knife dissection and modified it for an easier and faster performance. Here, we describe the precise surgical technique of our CDASC technique and introduce the benefits of our technique through its short and long-term follow-up results.

\section{Subjects and Methods}

\section{Design and patient enrollment}

This retrospective study examined 492 children younger than 18-year-old who underwent adenotonsillectomy via the CDASC technique by the senior author (S.N.P.) at Seoul St. Mary's Hospital from January 2010 to December 2018. After obtaining approval from the Institutional Review Board (KC13RISI0591), the medical and operative records were reviewed and collected data were entered into a spreadsheet. A waiver of consent was approved for this retrospective chart review study.

All enrolled children had at least one of obstructive symptoms such as long-lasting nocturnal snoring, sleep apnea, or open-mouth breathing. All patients were admitted on the day of surgery and, after confirming that there were no complications such as fever, dehydration, or bleeding, they were discharged the day after surgery. All patients were asked to visit the hospital (or nearest ENT clinic) immediately if they noted any kind of postoperative bleeding, even when it was minimal. Parents were instructed to feed their child on a normal diet, a regular diet as same as before the surgery, as soon as possible after hospital discharge, if pain was tolerable. A normal diet was defined as a dietary pattern patients consumed before the surgery. All detailed information related to surgical outcomes including the presence of bleeding, postoperative days to a normal diet (as a measure of postoperative pain), and improvement of obstructive symptoms was obtained from the parents and were recorded during regular follow-up visits through a detailed questionnaire. No patients enrolled in this study missed their 1st scheduled follow-up visit at post-operative 14 days.

From October 2010 to December 2012, 87 children who underwent this surgery were specifically asked to visit our outpatient clinic 6 and 12 months after the surgery to analyze the long-term surgical outcomes. Lateral neck radiography was obtained preoperatively and 6 and 12 months postoperatively from all attending patients. Each radiograph was evaluated by an author who was blinded to the patient's clinical status. The adenoid to nasopharyngeal $(\mathrm{A} / \mathrm{N})$ ratio was calculated preoperatively as defined by Fujioka, et al. ${ }^{7}$ At their followup visits, intraoral photography was also taken for each patient using a $2.7 \mathrm{~mm}$ rigid endoscope and post-tonsillectomy 

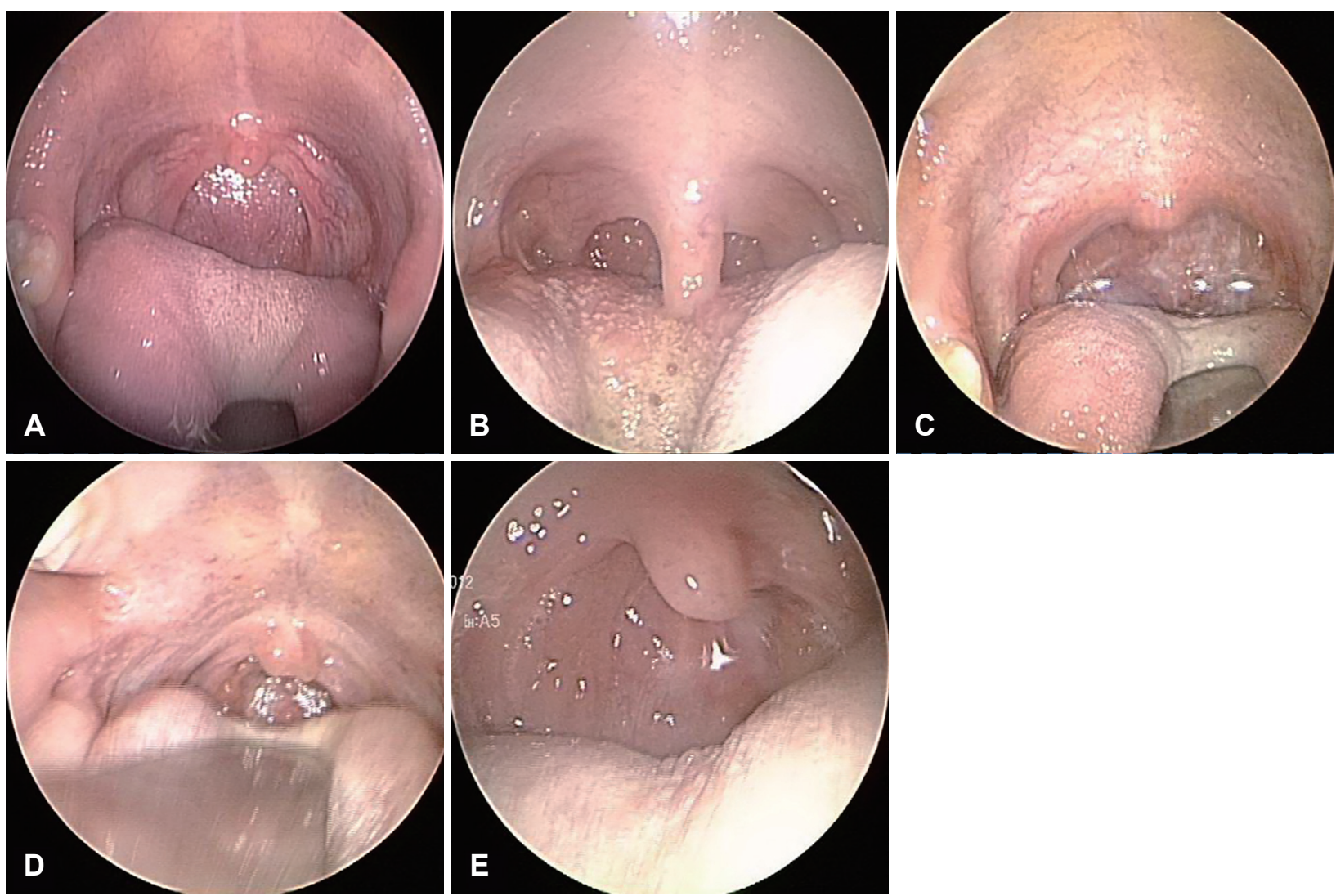

Fig. 1. Grading system for post-tonsillectomy oropharyngeal scarring. Grade 0: normal; freely movable tonsillar pillars and uvula, no scar formation $(A, B)$, grade 1: minimal scarring change around the uvula or tonsillar pillars; edematous change of uvula (C, D), grade 2: mild adhesion between the uvula and tonsillar pillars (E), grade 3: severe adhesion; markedly decreased mobility of pillars and uvula (none shown).

oropharyngeal scarring was graded separately by two independent investigators based on our grading system (Fig. 1).

\section{Surgical technique}

For complete adenoidectomy and hemostasis, a combination of adenoidal curettage and suction electrocauterization (Suction Coagulator 8 Fr. With Finger Valve Vent, ValleyLab ${ }^{\mathrm{TM}}$, Minneapolis, MN, USA) under a small laryngeal mirror view was performed. After initial adenoidal curettage, nasopharynx was packed with epinephrine gauze to stop the bleeding. The packing was removed after consecutive tonsillectomy. The adenoid bed was meticulously rechecked with a mirror to make sure no adenoid tissue was remaining. Additional curettage was done if there were a large amount of tissue left. If there were only small amount of tissue left, suction electrocauterization was used with cutting mode for remnant tissue removal and with coagulation mode for coagulation of adenoid bed at an energy of $50 \mathrm{~W}$.

For cold knife tonsillectomy, the classic method of a No. 12 knife incision at anterior pillar of tonsillar fossa, dissection with a cotton ball and hockey stick, and amputation using the tonsil snare was applied. No epinephrine or lidocaine injection was used before incision or during dissection, nor any magnification devices. Hemostasis was carefully achieved by two or three ties at the exact bleeding points and at the remnant tonsil tissues around the inferior pole. Owing to cold knife dissection without heat injury, small perforating vessels coming from the tonsillar beds were easily identified and tied or cauterized at the site of bleeding. Remnant tonsil tissue around the inferior poles were tied with 3-0 Black Silk. For better hemostasis, electrocauterization using fine bayonet forceps and monopolar diathermy (Force FX Electrosurgery, ValleyLab ${ }^{\mathrm{TM}}$ ) at an energy of $30 \mathrm{~W}$ was added to the traditional cold dissection technique by Crowe, ${ }^{2)}$ which recommended ligating bleeding points with silk ligatures.

Tonsillar beds were meticulously evaluated for further bleeding by cotton balls soaked with $\mathrm{H}_{2} \mathrm{O}_{2}$. Tannic acid was applied to the fossa for better hemostasis with superficial chemical cauterization (Fig. 2). 

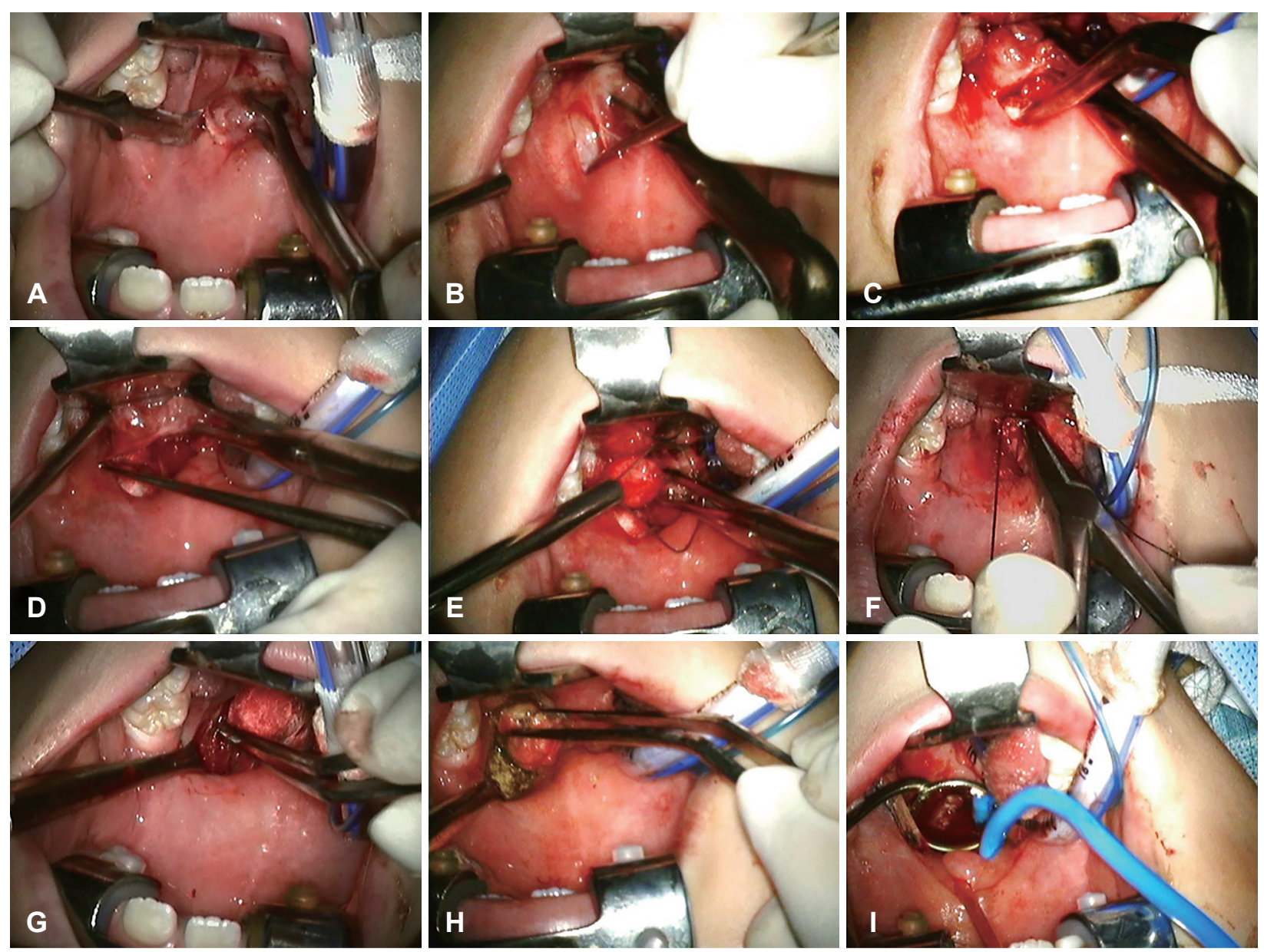

Fig. 2. Intraoperative photographs of cold-knife dissection with adjunctive suction cauterization technique. Superior mucosal incision was made close to the tonsil (A). The peritonsillar plane was identified with Hurd pillar retractor (B) and a cotton ball (C). The tonsil was dissected from the fossa bed with the dissector (D). A tonsil snare was used to amputate the tonsil at the inferior pole (E). Hemostasis was achieved by ties at the inferior pole (F) and fine diathermy at the tonsillar bed $(\mathrm{G})$. Tannic acid $(\mathrm{H})$ was applied to the fossa for better hemostasis. After the right tonsil was removed in the same way, removal of adenoid remnants and control of bleeding were performed with suction cautery under mirror inspection (I).

\section{Statistical analysis}

Descriptive analysis and frequency analysis were performed using the SPSS software (ver. 24; IBM Corp., Armonk, NY, USA). A paired sample $t$ test was used for the comparison of preoperative and postoperative paired $\mathrm{A} / \mathrm{N}$ ratio levels to evaluate adenoid regrowth. The statistical significance level was established at $p<0.05$.

\section{Results}

\section{Analysis of short-term postoperative complications}

Four hundred and ninety-two children [295 male (60.0\%); 197 female (40.0\%)] were included in this study. The mean age at surgery was $6.50 \pm 2.82$ years (range $2-17$ years). The main indication for adenotonsillectomy included snoring (68.1\%), sleep apnea (8.9\%), and recurrent tonsillitis (31.9\%).
All enrolled subjects were discharged 24 hours after surgery and there were no postoperative bleeding events during the admission period. None of the operated patients made an unscheduled visit to the hospital due to hemorrhage after 24 hours, and there were no bleeding episodes during the postoperative healing period according to the parents at the first regular visit at postoperative 14 days, which indicates rates of $0 \%$ for immediate and delayed postoperative bleeding with this surgical technique (Table 1), during the average followup period of $10.23 \pm 4.05$ months (median; 12.5 months).

Return to preoperative regular diet was achieved in 3.14 \pm 0.80 days (range $2-7$ days). Thirty-eight children (7.7\%) took 2 days and 404 children (82.1\%) took 3 days to resume a normal diet. Therefore, $89.8 \%$ of the patients showed normal diet consumption and activity within 3 days (Fig. 3). 
Table 1. Demographic data and post-op bleeding rates in pediatric patients undergoing adenotonsillectomy with the cold-knife dissection with adjunctive suction cauterization technique

\begin{tabular}{lc}
\hline \multicolumn{1}{c}{ Clinical factor } & Value $(\mathrm{n}=492)$ \\
\hline Age (years) & $6.50 \pm 2.82(2-17)$ \\
Sex (M:F) & $295(60.0): 197(40.0)$ \\
$\begin{array}{l}\text { Immediate post-op bleeding rate } \\
(<24 \text { hours after surgery) }\end{array}$ & $0 / 492(0)$ \\
$\begin{array}{c}\text { Delayed post-op bleeding rate } \\
(\geq 24 \text { hours after surgery) }\end{array}$ & $0 / 492(0)$ \\
\hline
\end{tabular}

post-op: postoperative

\begin{tabular}{|c|c|c|}
\hline \multicolumn{2}{|c|}{ Days to normal diet after surgery } & Day 5 Day 6 Day 7 \\
\hline Post-op. & No. of patients & \\
\hline Day 2 & 38 & \\
\hline Day 3 & 404 & \\
\hline Day 4 & 20 & \\
\hline Day 5 & 16 & \\
\hline Day 6 & 1 & Day 3 \\
\hline Day 7 & 13 & $82.1 \%$ \\
\hline Total & 492 & \\
\hline
\end{tabular}

Fig. 3. Distribution of time (days) taken to return to normal diet after surgery.

\section{Analysis of long-term postoperative complications}

Intraoral photographs of 20 patients at 6 months and 32 patients at 12 months were available postoperatively. Based on our grading system for post-tonsillectomy oropharyngeal scarring, $77.5 \%$ of patients' postoperative 6-month photographs of the mouth were graded as normal (grade 0 ), $17.5 \%$ were graded as grade $1,5 \%$ as grade 2 , and none as grade 3 . Similarly, $79.7 \%$ of 12 -month photographs of the mouth were graded as 0 (Fig. 4), 20.3\% as 1, and none as 2 or 3 .

Lateral neck radiography was available from 87 patients preoperatively, 76 patients at 6 months and 41 patients at 12 months, postoperatively for $\mathrm{A} / \mathrm{N}$ ratio comparison. When the preoperative and postoperative $\mathrm{A} / \mathrm{N}$ ratios were compared, statistically significant decreases in $\mathrm{A} / \mathrm{N}$ ratio were found both in the 6-month follow-up group ( $p=0.021)$ and 12-month follow-up group $(p<0.001)$ (Table 2). Among these patients, 31 children had sequential radiographs at 6 and 12 months. The average preoperative $\mathrm{A} / \mathrm{N}$ ratio of this group was $0.621 \pm$ 0.089 , which was significantly reduced to $0.364 \pm 0.066$ at postoperative 6 months $(p<0.001)$, but there was no statistical difference in $\mathrm{A} / \mathrm{N}$ ratio between postoperative 6 and 12 months $(p=0.719)$ (Fig. 5).

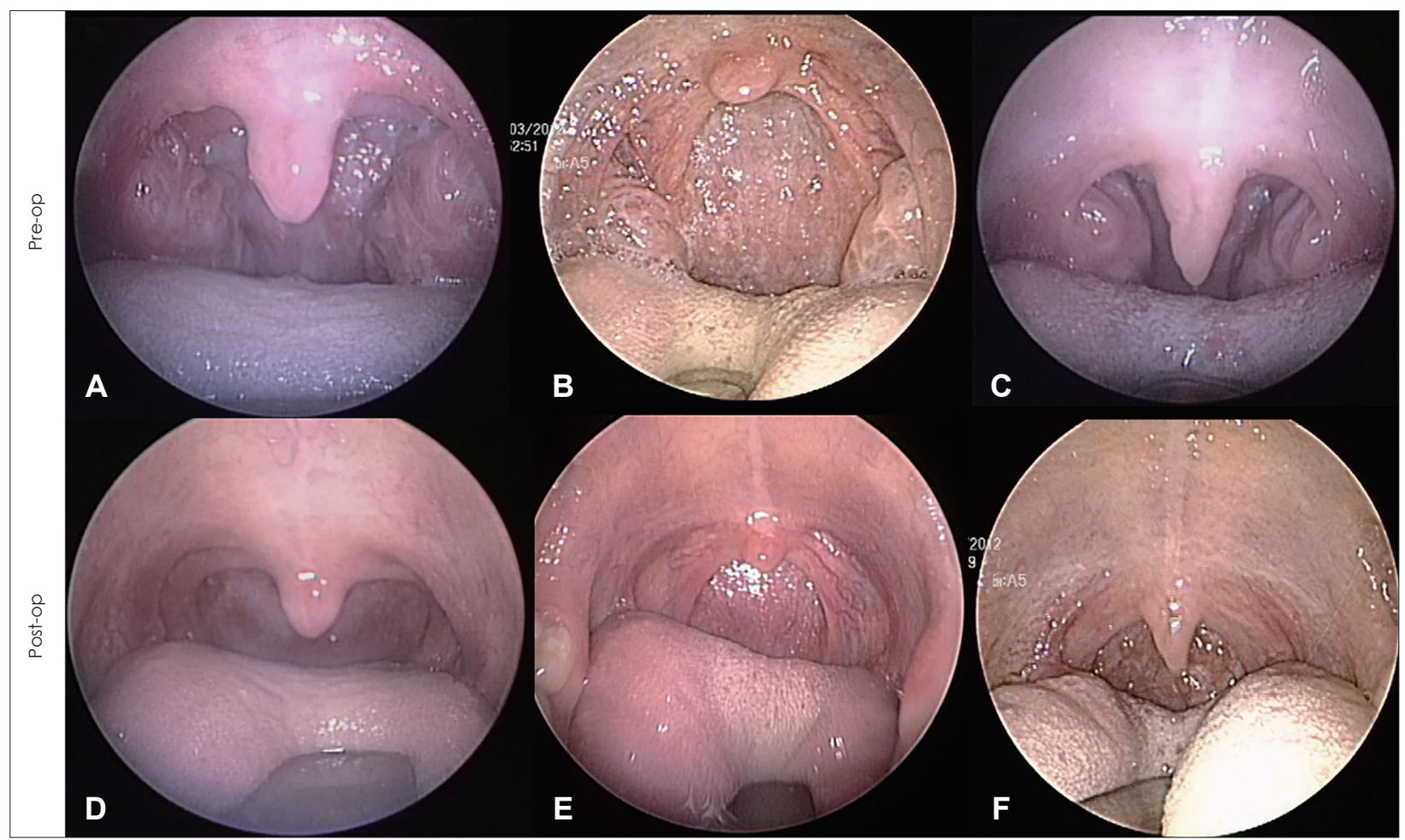

Fig. 4. Representative endoscopic findings of the oropharyngeal aperture pre-op and 12 months after the cold-knife dissection with adjunctive suction cauterization adenotonsillectomy (post-op). Post-op intraoral photographs (D-F) show the normal appearance of the oropharynx including the uvula, soft palate, and bilateral pillars without any scar formation compared with preoperative photos (A-C). pre-op: preoperative, post-op: postoperative. 
Table 2. Comparison of pre-op and post-op A/N ratios after adenotonsillectomy via the cold-knife dissection with adjunctive suction cauterization technique

\begin{tabular}{lccc}
\hline & $\begin{array}{c}\text { Pre-op } \\
\text { A/N ratio }\end{array}$ & $\begin{array}{c}\text { Post-op } \\
\text { A/N ratio }\end{array}$ & p-value* \\
\hline $\begin{array}{l}\text { 6-month follow-up } \\
\text { group ( } n=76)\end{array}$ & $0.607 \pm 0.102$ & $0.426 \pm 0.651$ & 0.021 \\
$\begin{array}{l}\text { 12-month follow-up } \\
\text { group ( } n=41)\end{array}$ & $0.628 \pm 0.093$ & $0.366 \pm 0.071$ & $<0.001$ \\
& & &
\end{tabular}

* $\mathrm{p}$-value for Pearson's chi-square test. A/N: adenoid to nasopharynx, pre-op: preoperative, post-op: postoperative

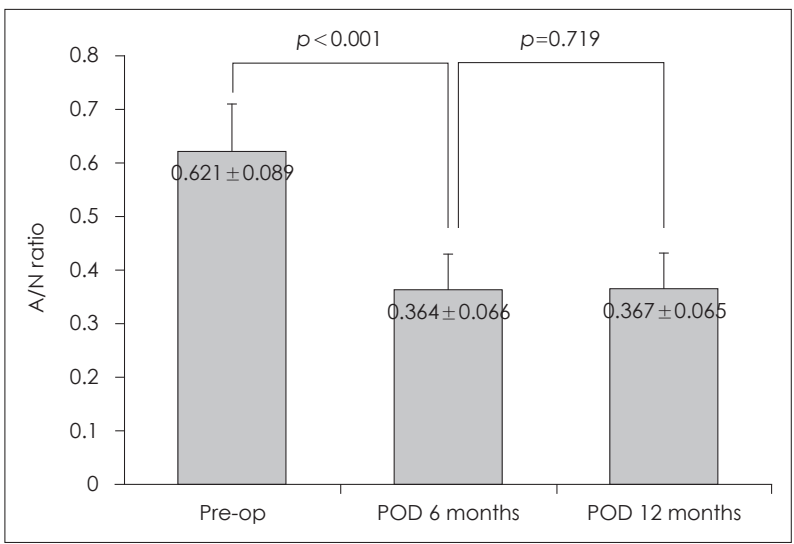

Fig. 5. Serial changes in the mean $\mathrm{A} / \mathrm{N}$ ratio after adenotonsillectomy $(n=31)$; measurement pre-op and at 6 months and 12 months postoperative. A/N: adenoid to nasopharynx, pre-op: preoperative, POD: postoperative day.

Obstructive symptoms of all 87 children had either improved or been resolved, as judged by their parents. Moreover, no recurrences of symptoms were detected during the follow-up period of 6-12 months.

\section{Discussion}

Adenotonsillectomy is one of the most frequently applied and oldest surgical procedures in otorhinolaryngology, with more than 530000 procedures performed annually in children younger than 15 years. ${ }^{8)}$ Generally, the indications for surgery are primarily related to chronic upper airway obstruction in conjunction with adenotonsillar hypertrophy, which manifests as snoring, obstructive sleep apnea, or chronic infectious conditions such as chronic recurrent tonsillitis. ${ }^{9)}$ Because adenotonsillectomy is such a common surgery in the field of pediatric otorhinolaryngology, the risks and long-term effects are often overlooked, and there are not enough discussion regarding what the best operative technique and perioperative management is. Over the years, techniques for adenotonsillectomy developed in a way that are more convenient for surgeon, utilizing electromechanical instruments such as monopolar electrocautery and other power-assisted instruments such as microdebrider and coblator. ${ }^{10)}$ However, most of the studies that dealt with these new techniques focused simply on the amount of operative blood loss and the rate of post-operative hemorrhage, and not much on the perioperative discomfort level of patients, never on the long-term result following the surgery. Adenotonsillectomy should ideally be fast and easy to perform with low immediate complication for the sake of the surgeon, but at the same time it should cause minimal pain for the patients to return to normal life pattern as early as possible, without altering anatomic structures. Furthermore, although adenotonsillectomy is considered relatively safe operation, the chances for complications such as post-tonsillectomy bleeding, oropharyngeal scarring, and adenoid regrowth, are still encountered infrequently, and can be critical especially to pediatric patients.

A variety of studies have dealt with postoperative hemorrhage as the most serious complication of tonsil surgeries. Rates of immediate ( $<24$ hours) and delayed ( $>24$ hours) hemorrhage ranged from $0.2 \%$ to $2.2 \%$ and from $0.1 \%$ to $3 \%$, respectively. ${ }^{11)}$ Because of varying definitions of what is considered a postoperative bleeding episode and differences in study designs, the reported hemorrhage rates and their risk factors vary considerably among studies. In our study, postoperative hemorrhage was defined as any sort of oral bleeding event reported during follow-up. Despite the broad definition, our CDASC technique had $\% \%$ rate for both immediate and delayed post-tonsillectomy bleeding over the 7 years of study period. Although it is generally accepted that the postoperative bleeding rate is lower in children than in adults, bleeding is more dangerous in children because of the higher possibility of aspiration and smaller reservoir of systemic circulation. ${ }^{12}$ Therefore, it is necessary to focus on lowering the hemorrhage rate after adenotonsillectomy, especially in children. The main risks of the cold surgical technique were thought to be higher intraoperative blood loss and longer operation time. But recent studies suggest that although the cold techniques do indicate higher intraoperative blood loss, it has rather shorter surgical dissection time, ${ }^{13)}$ less pain at postoperative 7 th day, and lower postoperative hemorrhage rate when compared to the hot technique. ${ }^{13,14)}$ Hot surgical techniques may increase the risk of delayed hemorrhage by 3-fold when compared to cold steel tonsillectomy without any use of hot instruments, ${ }^{15)}$ due to primary eschar formation from heat injury and late sloughing of eschar during healing process. Thus, we used a modified version of traditional cold 
dissection technique to maximize the merits of the cold technique. After tonsillectomy with a cold steel dissector and snare, which shows better visualization of bleeding points, hemostasis was achieved by tightly placing ties at remnant tonsil tissue around the inferior pole. The arterial blood supply of the tonsil enters primarily at the lower pole ${ }^{9)}$ and secure hemostasis around the lower pole using ties, not cauterization, is crucial to prevent immediate bleeding. Furthermore, all visualized small vessels and bleeding points were coagulated with fine bayonet forceps and monopolar diathermy with our technique. The sharp tip of bayonet forceps makes it possible to coagulate tiny engorged vessels selectively, so there is less eschar formation on the tonsillar bed. We believe our selective coagulation method aiming to prevent eschar formation likely prevented post-tonsillectomy bleeding.

Throat pain is another significant cause of pediatric posttonsillectomy morbidity, affecting perioperative and postoperative quality of life. The pain following tonsillectomy is mainly due to irritation of open nerve endings of the glossopharyngeal and vagus nerves and spasms of the exposed pharyngeal and palatal muscles from mechanical or thermal damage. ${ }^{16)}$ Despite its frequency and clinical importance, it is not easy to find an effective method to grade postoperative throat pain, especially in children. It is inappropriate to extrapolate from the findings of adult tonsillectomy and apply to the pediatric population, because children's responses are much different from those of adults. ${ }^{17)}$ There have been many studies that tried to evaluate children's post-tonsillectomy pain with measures such as the visual analogue scale (VAS), ${ }^{1,18,19)}$ days of pain, ${ }^{1)}$ amount of analgesic requirement, ${ }^{1,17)}$ time taken to re-establish a normal diet, ${ }^{1,15-19)}$ and limitation of activity. ${ }^{1,17,18)}$ VAS is the most common and easy-to-use method to measure pain, but it is often difficult to collect self-reported pain scores in children especially in the immediate postoperative period. ${ }^{20)}$ In this study, we decided to use "time taken to return to normal diet" as an indicator of pain, as this method is a more objective measure than VAS scores, and can apply to even younger children who cannot express their pain properly. Numerous studies have shown that electrodissection causes increased postoperative pain in comparison with cold dissection tonsillectomy. Nunez, et al. ${ }^{17)}$ reported that the bipolar diathermy group took statistically 2.5 days longer to return to a normal diet than did the cold dissection group. Similarly, the mean time to regain normal diet was $9.3 \pm 1.7$ days in a bipolar cautery group and $7.0 \pm 1.5$ days in a cold dissection group in another study. ${ }^{19)}$ Our results, a mean of $3.14 \pm 0.80$ days, showed an even faster return to normal diet than the outcomes of many previous studies. Overall, $89.8 \%$ of the children showed normal diet consumption and activity within 3 days. We believe that the fast recovery time was due to our CDSAC technique, which makes it possible to perform a more precise and natural dissection along the peritonsillar plane, while the electrocauterizing dissection could often disrupt the plane unintentionally. Preservation of normal peritonsillar tissue accelerates postoperative wound healing, and allows children to swallow solid food less painfully. In addition, minimal thermal coagulation was conducted on selective vessels only, allowing least thermal injury to adjacent structures, including pain nerve fibers. ${ }^{19)}$

As for late complication that can result following tonsillectomy, oropharyngeal stenosis (OPS) must be considered. OPS may appear as a cicatricial scar that is visible in the oropharynx and it is caused by adhesion of the anterior pillars and inferior tonsillar fossae to the tongue base, which accordingly narrows the oropharyngeal aperture. Multiple risk factors, including excessive cautery, bleeding, a predisposition to keloid formation, and deep dissection in the region of the inferior tonsillar poles with removal of adjacent lingual tonsil tissue, have been known to be associated with the development of OPS. Although OPS has been described as a rare complication of tonsillectomy with or without adenoidectomy, it is a significant potential complication of multilevel, single-stage upper airway surgery involving lingual tonsillectomy in children compared to adults. ${ }^{21)}$ Unfortunately, many contemporary accounts of adenotonsillectomy complications do not mention it, and the importance of preventing OPS is often ignored. In our analysis of the incidence of oropharyngeal scarring (as a mild form of OPS), most of the children (79.7\%) who underwent adenotonsillectomy via our technique showed an anatomically normal-looking oropharynx, including uvula, soft palate, and bilateral pillars, without any scar formation at 1 year after surgery, based on our new grading system (Fig. 1). Rest of the children (10.3\%) showed only minimal scar changes around the uvula. Without an incidence of OPS, minimal oropharyngeal scarring did not cause any significant symptoms when compared to normal children. As mentioned earlier, our method of cold dissection without electrocautery possibly minimized the incidence of scar formation due to thermal injury of surrounding tissues. Moreover, a tonsil snare used to amputate the tonsil at the inferior pole, instead of deep dissection into that region, allowed minimal manipulation of the lingual tonsils or tongue base, possibly preventing a develop- 
ment of OPS.

Enlarged adenoid is one of the main reasons for pediatric adenotonsillectomy, as it plays a central role in nasopharyngeal airway obstruction, sleep-disordered breathing and recurrent otitis media. Fortunately, symptoms usually resolve completely or improve greatly after successful adenoidectomy. ${ }^{22,23)}$ Thus, there are few studies that analyzed long-term results of adenoidectomy through an objective examination of the nasopharynx. Correspondingly, the limited data in the medical literature give estimates of incidence of symptomatic adenoid regrowth as $<1 \%$ to $3 \%{ }^{24,25)}$ One of the reasons for this variation in incidence rate may be due to differences in the diagnostic tools and the definition of regrowth, depending on the researchers. ${ }^{26)}$ Adenoids can be diagnosed by several diagnostic methods such as nasopharyngeal endoscopy, ${ }^{27)}$ lateral neck radiography, ${ }^{28)}$ lateral cephalometry, ${ }^{26,27)}$ computed tomographic scan, ${ }^{29)}$ and MRI. ${ }^{30)}$ In our study, lateral neck radiography was performed three times until 1 year after the surgery to evaluate long-term postoperative changes of adenoid size using the $\mathrm{A} / \mathrm{N}$ ratio, at the same time minimizing radiation exposure, time, and cost for follow-up examination. We found that there was a significant decrease in the $\mathrm{A} / \mathrm{N}$ ratio, postoperatively. Moreover, our serial follow-up data on 31 children showed that the $\mathrm{A} / \mathrm{N}$ ratio significantly decreased at 6 months $(p<0.001)$ and kept statistically unchanged until 1 year after surgery $(p=0.719)$. In our CDASC surgical technique, the greater portion of the enlarged adenoid was removed by curette, following epinephrine soaked gauze packing of the nasopharynx for hemostasis. Then, adjunctive suction cauterization with mirror visualization allowed excellent exposure of the surgical field and complete removal of remnant adenoids while preserving the Eustachian cushions, leaving no residual adenoids for adenoid regrowth.

This study has few limitations. First, owing to the retrospective nature of the study, the extraction of data from the medical records may not completely describe the actual clinical status of each subject. Furthermore, the information associated with surgical outcomes, such as presence of any bleeding sign, days to normal eating, and improvement of obstructive symptoms, was collected from each parent's anamnestic answers at the 1st follow-up visit. Secondly, intraoral photographs used for postoperative evaluation was taken in only a small portion of all enrolled patients, which may result in selection bias. Finally, no comparisons were made with other techniques, so the relative safety and efficacy could not be determined. Nonetheless, our results are consistent with many re- cent studies that have suggested several advantages of the cold-knife tonsillectomy over the hot technique. A well-designed randomized controlled prospective study is planned in future to overcome these limitations.

In conclusion, recent trends in adenotonsillectomy have focused on techniques that are more convenient for surgeons. However, a successful adenotonsillectomy for pediatric patients should prioritize on ameliorating obstructive symptoms with minimal morbidity, at the same time minimizing distress that follows the operation. In this regard, we demonstrate the precise method and the short and long-term outcomes of the CDASC technique for the surgical removal of adenoid and tonsils. Our technique seems to have several noticeable advantages, including an earlier return to a regular diet, zero postoperative bleeding, less oropharyngeal scarring, and no occurrence of adenoid regrowth without recurrence of obstructive symptoms. We believe our CDASC technique is a useful, safe, and effective surgical technique for pediatric adenotonsillectomy.

\section{Acknowledgments}

None.

\section{Author Contribution}

Conceptualization: Jung Mee Park, Shi Nae Park. Data curation: Jae Sang Han, Yeonji Kim. Formal analysis: Jung Mee Park, Jae Hyun Seo, Shi Nae Park. Investigation: Jung Mee Park, Jae Sang Han, Yeonji Kim. Methodology: Shi Nae Park. Project administration: Jung Mee Park, Jae Sang Han. Resources: Shi Nae Park. Supervision: Jae Hyun Seo, Shi Nae Park. Validation: Shi Nae Park. Visualization: Jung Mee Park. Writing — original draft: Jung Mee Park. Writing — review \& editing: Jung Mee Park, Shi Nae Park.

\section{ORCID}

Shi Nae Park https://orcid.org/0000-0002-7614-9413

\section{REFERENCES}

1) Wilson YL, Merer DM, Moscatello AL. Comparison of three common tonsillectomy techniques: A prospective randomized, double-blinded clinical study. Laryngoscope 2009;119(1):162-70.

2) Crowe SJ, Watkins SS, Rothholz AS. Relation of tonsilar and nasopharyngeal infections to general systemic disorders. Bull Johns Hopkins Hosp 1917;28:1-63.

3) Roth JA, Pincock T, Sacks R, Forer M, Boustred N, Johnston W, et al. Harmonic scalpel tonsillectomy versus monopolar diathermy tonsillectomy: A prospective study. Ear Nose Throat J 2008;87(6): 346-9.

4) Lachanas VA, Hajiioannou JK, Karatzias GT, Filios D, Koutsias S, Mourgelas C. Comparison of LigaSure vessel sealing system, harmonic scalpel, and cold knife tonsillectomy. Otolaryngol Head Neck Surg 2007;137(3):385-9.

5) Baugh RF, Archer SM, Mitchell RB, Rosenfeld RM, Amin R, Burns JJ, et al. Clinical practice guideline: Tonsillectomy in children. Otolaryngol Head Neck Surg 2011;144(1 Suppl):S1-30.

6) Lehmann AE, Kozin ED, Sethi RKV, Wong K, Lin BM, Gray ST, 
et al. Resident responses to after-hours otolaryngology patient phone calls: An overlooked aspect of residency training? Laryngoscope 2018;128(5):E163-70.

7) Fujioka M, Young LW, Girdany BR. Radiographic evaluation of adenoidal size in children: Adenoidal-nasopharyngeal ratio. AJR Am J Roentgenol 1979;133(3):401-4.

8) Cullen KA, Hall MJ, Golosinskiy A. Ambulatory surgery in the United States, 2006. Natl Health Stat Report 2009;(11):1-25.

9) Shirley WP, Woolley AL, Wiatrak BJ. Pharyngitis and adenotonsillar disease. In: Flint PW, Cummings CW, Lund VJ, Niparko JK, Richardson MA, Robbins KT, et al., editors. Cummings Otolaryngology-Head and Neck Surgery. 5th ed. Philadelphia, PA: Mosby/Elsevier;2010. p.2782-802.

10) Stoker KE, Don DM, Kang DR, Haupert MS, Magit A, Madgy DN. Pediatric total tonsillectomy using coblation compared to conventional electrosurgery: A prospective, controlled single-blind study. Otolaryngol Head Neck Surg 2004;130(6):666-75.

11) Windfuhr JP, Chen YS, Remmert S. Hemorrhage following tonsillectomy and adenoidectomy in 15,218 patients. Otolaryngol Head Neck Surg 2005;132(2):281-6.

12) Kim JW, Mun SJ, Lee WH, Mo JH. Post-tonsillectomy hemorrhage in children: A single surgeon's experience with coblation compared to diathermy. Eur Arch Otorhinolaryngol 2013;270(1):339-44.

13) Sanlı A, Yildiz G, Erdogan BA, Paksoy M, Altin G, Ozcelik MA. Comparison of cold technique tonsillectomy and thermal welding tonsillectomy at different age groups. Prague Med Rep 2017;118(1): 26-36.

14) Lowe D, van der Meulen J, Cromwell D, Lewsey J, Copley L, Browne J, et al. Key messages from the national prospective tonsillectomy audit. Laryngoscope 2007;117(4):717-24.

15) The Royal College of Surgeons of England. National prospective tonsillectomy audit: Final report of an audit carried out in England and Northern Ireland between July 2003 and September 2004. London, UK: The Royal College of Surgeons of England;2005.

16) Freeman SB, Markwell JK. Sucralfate in alleviating post-tonsillectomy pain. Laryngoscope 1992;102(11):1242-6.

17) Nunez DA, Provan J, Crawford M. Postoperative tonsillectomy pain in pediatric patients: Electrocautery (hot) vs cold dissection and snare tonsillectomy--a randomized trial. Arch Otolaryngol
Head Neck Surg 2000;126(7):837-41.

18) Hesham A. Bipolar diathermy versus cold dissection in paediatric tonsillectomy. Int J Pediatr Otorhinolaryngol 2009;73(6):793-5.

19) Ozkırış M. Comparison of three techniques in pediatric tonsillectomy. Eur Arch Otorhinolaryngol 2012;269(5):1497-501.

20) Maunuksela EL, Olkkola KT, Korpela R. Measurement of pain in children with self-reporting and behavioral assessment. Clin Pharmacol Ther 1987;42(2):137-41.

21) Eleff DJ, Tien DA, Anne S. Oropharyngeal stenosis: A rare complication following adenotonsillectomy. Am J Otolaryngol 2016;37(3):207-9.

22) Buchinsky FJ, Lowry MA, Isaacson G. Do adenoids regrow after excision? Otolaryngol Head Neck Surg 2000;123(5):576-81.

23) Dearking AC, Lahr BD, Kuchena A, Orvidas LJ. Factors associated with revision adenoidectomy. Otolaryngol Head Neck Surg 2012; 146(6):984-90.

24) Joshua B, Bahar G, Sulkes J, Shpitzer T, Raveh E. Adenoidectomy: Long-term follow-up. Otolaryngol Head Neck Surg 2006;135(4): 576-80.

25) Monroy A, Behar P, Brodsky L. Revision adenoidectomy--a retrospective study. Int J Pediatr Otorhinolaryngol 2008;72(5):56570.

26) Kim SY, Lee WH, Rhee CS, Lee CH, Kim JW. Regrowth of the adenoids after coblation adenoidectomy: Cephalometric analysis. Laryngoscope 2013;123(10):2567-72.

27) Caylakli F, Hizal E, Yilmaz I, Yilmazer C. Correlation between adenoid-nasopharynx ratio and endoscopic examination of adenoid hypertrophy: A blind, prospective clinical study. Int J Pediatr Otorhinolaryngol 2009;73(11):1532-5.

28) Feres MF, Hermann JS, Cappellette M Jr, Pignatari SS. Lateral $\mathrm{X}$-ray view of the skull for the diagnosis of adenoid hypertrophy: A systematic review. Int J Pediatr Otorhinolaryngol 2011;75(1):1-11.

29) Farid M, Metwalli N. Computed tomographic evaluation of mouth breathers among paediatric patients. Dentomaxillofac Radiol 2010; 39(1):1-10.

30) Donnelly LF. Magnetic resonance sleep studies in the evaluation of children with obstructive sleep apnea. Semin Ultrasound CT MR 2010;31(2):107-15. 